\title{
Aplikasi remotely operated vehicle (ROV) dalam penelitian kelautan dan perikanan di sekitar perairan Sulawesi Utara dan Biak Papua
}

Aplication of remotely operated vehicle (ROV) on marine and fisheries research in the waters of North Sulawesi dan Biak Papua

\author{
TiRZA H. SAMOSIR ${ }^{1}$, KAWILARANG W.A.MASENGI $^{1 *}$, PATRICE N.I. KALANGI ${ }^{1}$, \\ MASAMITSU IWATA ${ }^{2}$ dan IXCHEL F. MANDAGI ${ }^{1}$

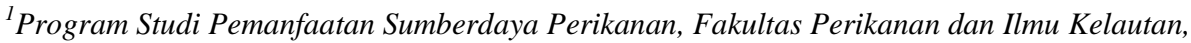 \\ Universitas Sam Ratulangi, Manado 95115 \\ ${ }^{2}$ Aquamarine Fukushima, Iwaki, Fukushima - Japan 9718101
}

\begin{abstract}
Marine conditions at a specific depth are not easily understood thoroughly if only relies on the ability of human beings without supporting facilities such as the availability of adequate equipment and technology, like Remotely Operated Vehicle (ROV). ROV is an underwater robot controlled by the people who have been professional to control the instrument. Using the ROV in the field of marine and fishery studies can simplify the process of research in marine organisms. ROV is classified by size, weight and strength are categorized as follows: Micro ROV, Mini ROV, General ROV, Light Workclass, Heavy Workclass and Trenching/Burial. The present study used the General ROV length $1076 \mathrm{~mm}$, width $640 \mathrm{~mm}$ and height $515 \mathrm{~mm}$. The research was carried out in two locations in the Northern Sulawesi and Biak Papua Province waters.
\end{abstract}

Keywords: ROV, underwater robot, North Sulawesi, Biak Papua Province

\begin{abstract}
ABSTRAK
Kondisi perairan laut pada kedalaman tertentu sangatlah tidak mudah dipahami secara menyeluruh jika hanya mengandalkan kemampuan manusia tanpa didukung oleh fasilitas pendukung seperti ketersediaan peralatan dan teknologi yang memadai, seperti Remotely Operated Vehicle (ROV). ROV merupakan robot bawah air yang dikontrol oleh orang yang telah professional untuk mengendalikan alat tersebut. Dalam bidang kelautan dan perikanan penelitian dengan menggunakan ROV dapat mempermudah proses penelitian organisme-organisme laut dalam. ROV diklasifikasikan berdasarkan ukuran, berat dan kekuatannya yang dikategorikan sebagai berikut: Micro ROV, Mini ROV, General ROV, Light Workclass, Heavy Workclass dan Trenching/Burial. Penelitian ini menggunakan General ROV dengan panjang $1076 \mathrm{~mm}$, lebar $640 \mathrm{~mm}$ dan tinggi $515 \mathrm{~mm}$. Penelitian dilaksanakan di dua tempat yakni di perairan Sulawesi Utara dan Biak Provinsi Papua.
\end{abstract}

Kata-kata Kunci: ROV, robot bawah air, Sulawesi Utara, Biak Provinsi Papua

\section{PENDAHULUAN}

Kondisi perairan laut pada kedalaman tertentu tidaklah mudah dipahami secara menyeluruh jika hanya mengandalkan kemampuan manusia tanpa didukung fasilitas pendukung lainnya seperti ketersediaan peralatan dan teknologi yang memadai. Ada beberapa faktor penyebab

\footnotetext{
*Penulis untuk penyuratan; e-mail: sabanib@yahoo.com
}

keterbatasan manusia untuk menyelami laut dalam di antaranya adalah tekanan setiap penambahan kedalaman laut sebesar $10 \mathrm{~m}$ akan menyebabkan bertambahnya tekanan sebesar 1 atmosfer sehingga semakin dalam perairan maka semakin tinggi pula tekanan yang tidak sesuai dengan lingkungan hidup manusia.

Selain dengan kondisi alam seperti itu, faktor suhu serta kurangnya pencahayaan di dasar laut 
menyebabkan jarak pandang berkurang, oleh karena itu dibutuhkan teknologi yang bisa mengeksplorasi potensi sumberdaya perikanan dan kelautan. Salah satu peralatan yang telah dikembangkan untuk mengatasi kendala tersebut adalah Remotely Operated Vehicle (ROV). Penelitian dengan menggunakan ROV, merupakan salah satu cara untuk menanggulangi keterbatasan manusia di dalam perairan tanpa harus menyelam.

ROV merupakan teknologi bawah air yang dikontrol oleh seseorang yang sudah profesional pada saat pengoperasian. Penelitan mengenai ROV juga sangat membantu, khususnya dalam bidang kelautan dan perikanan untuk mengetahui sejauh mana peranan ROV dalam membantu keterbatasan manusia di dalam air ketika melakukan penelitian suatu obyek yang ada dalam laut.

\section{METODE PENELITIAN}

Penelitian ini dikerjakan dengan menggunakan metode survei yang didasarkan pada pendekatan secara deskriptif. Metode survei adalah penyelidikan yang dilakukan untuk memperoleh fakta-fakta dari gejala-gejala yang ada dan mencari keterangan secara faktual subjek yang di teliti yang hasilnya dapat digunakan dalam membuat rencana dan pengambilan keputusan di masa mendatang. Adapun metode deskriptif ialah suatu metode dalam meneliti status suatu kelas peristiwa pada masa sekarang. Tujuannya ialah untuk membuat deskripsi atau gambaran secara sistematis faktual dan akurat tentang fakta-fakta dan sifat-sifat serta hubungan antara fenomena yang diselidiki (Nasir, 1993).

\section{HASIL DAN PEMBAHASAN}

\section{Profil suhu perairan}

Profil pengukuran suhu di perairan Kalasey Sulawesi Utara dan Tanjung Samber Biak masingmasing dilakukan di 4-5 stasiun dengan kedalaman pengoperasian ROV berbeda-beda. Pada Gbr. 1\&2 ditampilkan profil suhu perairan Kalasey dan perairan Tanjung Samber.

Nilai suhu pada perairan Kalasey dan Tanjung Samber berdasarkan waktu pengukuran menunjukkan tidak terdapat perbedaan yang signifikan atau cenderung homogen. Hal ini sesuai dengan yang dijelaskan oleh Ross (1970) dan Wyrtki (1961 dalam Dwi, 2010) bahwa lapisanlapisan stratifikasi dalam perairan disebabkan oleh beberapa faktor misalnya untuk lapisan permukaan dipengaruhi oleh curah hujan, penguapan, dinamika gerakan masa air, kecepatan angin yang bertiup di atasnya yang menyebabkan terjadinya gaya friksi antara angin daratan dan angin laut, sehingga akan menyebabkan pergerakan masa air dan terjadinya proses pengadukan air laut. Besarkecilnya kecepatan angin yang berhembus di atas permukaan laut akan mempengaruhi pengadukan masa air yang selanjutnya akan mempengaruhi ketebalan lapisan homogen. Sugiarto dkk (1980) menginfomasikan bahwa daerah Teluk Manado memiliki suhu permukaan sekitar $29^{\circ} \mathrm{C}$ dan daerah termoklin terjadi pada kedalaman 50-110 m.

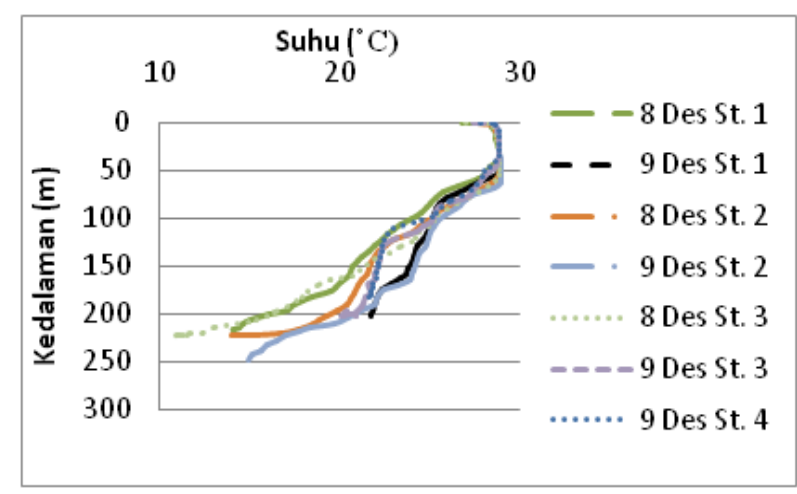

Gambar 1. Profil suhu stasiun 1-4 Kalasey (Sulawesi Utara)

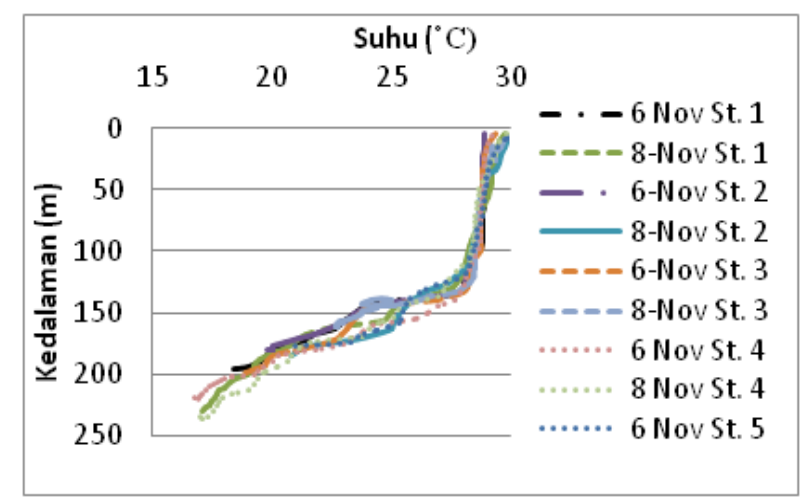

Gambar 2. Profil suhu stasiun 1-5 Tanjung Samber (Biak)

Dapat juga dilihat pada grafik dari stasiun 1-5 bahwa hasil pengukuran suhu dengan ROV di perairan Tanjung Samber pada lapisan permukaan berkisar antara $29-30^{\circ} \mathrm{C}$ dan pada kedalaman 130-150 m terjadi perubahan suhu secara tiba-tiba dimana lapisan ini dikenal sebagai lapisan termoklin. Pada lapisan mixed layer yaitu lapisan 
permukaan hingga kedalaman $50 \mathrm{~m}$, suhu menunjukkan nilai yang lebih tinggi daripada lapisan di bawahnya. Makin ke lapisan dalam, suhu air laut makin dingin. Hal ini teramati pada lapisan dalam yaitu di bawah 200-250 meter.

Dari grafik suhu di atas kebanyakan organisme laut dalam yang ditemukan dengan menggunakan ROV berada pada kisaran kedalaman 148-219 meter dengan suhu rata-rata $16-20^{\circ} \mathrm{C}$.

\section{Profil oksigen terlarut}

Profil oksigen terlarut (dissolved oxygen, DO) di perairan Kalasey dan Tanjung Samber diberikan pada Gbr. 3\&4.

DO dalam air laut turut aktif dalam proses biologi dan kimia di dalam laut. Sebagian besar DO berasal dari atmosfer dan permukaan laut. DO dan konsentrasi nutrient berbanding terbalik satu dengan yang lainnya, dimana ketika konsentrasi nutrient tinggi, DO menjadi rendah (Gross, 1990). Dapat dilihat pada profil stasiun 1-5 di Tanjung Samber dan Stasiun 1-4 Kalasey bahwa DO pada saat pengoperasian ROV nilainya relatif sama yaitu berkisar antara 5-7 ppm dan berada dalam kategori normal. Dalam suatu kolam jika kandungan DO sama dengan atau lebih besar dari $5 \mathrm{mg} / \mathrm{l}$, maka proses reproduksi dan pertumbuhan ikan akan berjalan dengan baik (Boyd dalam Maswira, 2009).

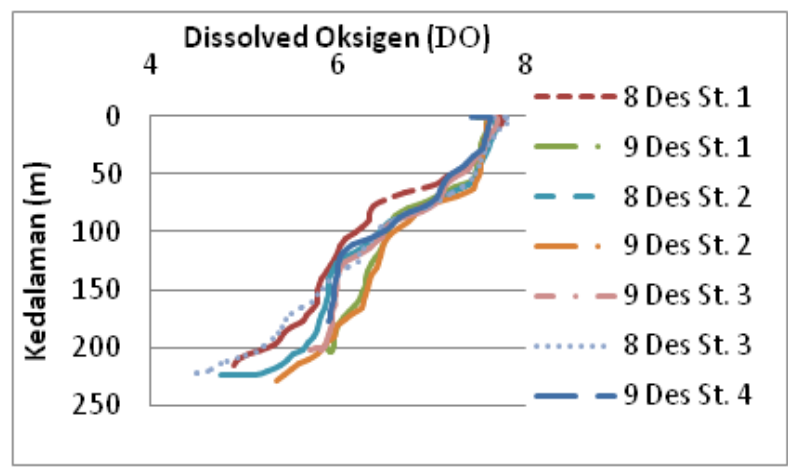

Gambar 3. Profil DO stasiun 1-4 Kalasey (Sulawesi Utara)

Faktor-faktor yang mempengaruhi banyaknya DO dalam suatu perairan (Anonimous, 2010) adalah:

1. Pergerakan permukaan air. Pergerakan air berupa riak air maupun gelombang akan mempercepat difusi udara ke dalam air.

2. Suhu. Suhu berpengaruh pada kejenuhan (kapasitas air menyerap oksigen). Makin tinggi suhu maka makin sedikit oksigen dapat larut.
3. Tekanan udara. Tekanan udara berhubungan dengan ketinggian suatu daerah dari permukaan laut. Makin tinggi suatu daerah maka makin rendah tekanan udaranya sehingga makin rendah pula kadar oksigen terlarut.

4. Salinitas. Makin tinggi salinitas maka makin sedikit oksigen yang dapat larut.

5. Tanaman air. Tanaman air terutama ganggang, tentunya berhubungan dengan proses fotosintesis yang memerlukan sinar matahari. Bila sinar matahari sedikit maka proses fotosintesis terhambat sehingga oksigen terlarut pun sedikit.

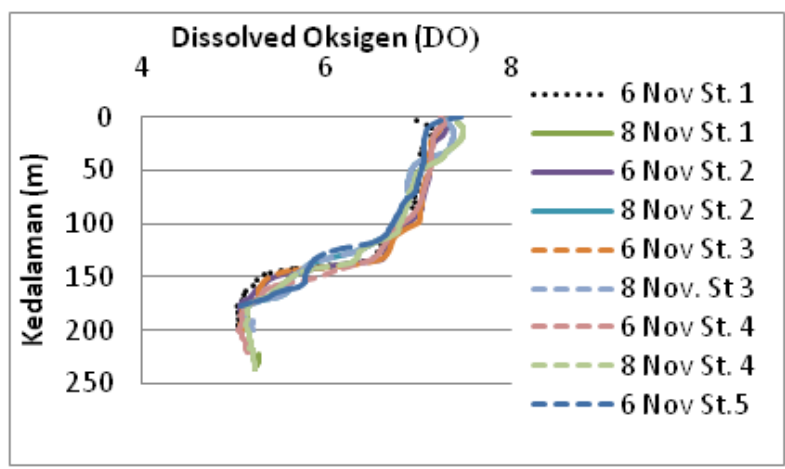

Gambar 4. Profil DO stasiun 1-5 Tanjung Samber (Biak)

Semakin besar nilai DO dalam air, mengindikasikan air tersebut memiliki kualitas yang baik. Sebaliknya jika nilai DO rendah, dapat diketahui bahwa air tersebut telah tercemar. Pengukuran DO juga bertujuan melihat sejauh mana badan air mampu menampung biota air seperti ikan dan mikroorganisme (Whephe, 2011)

\section{Tabulasi Data Perikanan}

Ikan-ikan yang ditemukan dalam penelitian ini terdiri dari 8 jenis dengan panjang (diukur dengan laser ROV) berkisar antara $18-22 \mathrm{~cm}$. Ikan-ikan ini berada pada kedalaman antara 160-220 m dengan suhu perairan antara $10,9^{\circ} \mathrm{C}$ dan $20,6^{\circ} \mathrm{C}$. Data selengkapnya dapat dilihat pada Tabel 1 .

\section{KESIMPULAN}

Kontribusi ROV dalam dunia kelautan dan perikanan sangat besar manfaatnya dan hal itu dapat dilihat dari penemuan-penemuan yang dilakukan dengan menggunakan alat ini. Dari hasil penelitian dengan menggunakan ROV di perairan Sulawesi Utara dan Biak Propinsi Papua dapat disimpulkan bahwa alat ini tidak hanya memiliki 
kemampuan untuk melihat atau merekam organisme di laut dalam, namun juga dapat merekam suhu dan DO di suatu wilayah perairan. Di perairan Kalasey suhu maximum $28,95^{\circ} \mathrm{C}$ dan minimum $23,44^{\circ} \mathrm{C}$ dan di perairan Tanjung Samber suhu maximum $29,43^{\circ} \mathrm{C}$ dan minimum $28,38^{\circ} \mathrm{C}$.

Tabel 1. Ikan-ikan yang ditemukan dan kondisi perairan selama pengoperasian ROV

\begin{tabular}{lllcccc}
\hline Tanggal & \multicolumn{1}{c}{ Nama Ilmiah } & Nama Lokal & Panjang $(\mathrm{cm})$ & Suhu $\left({ }^{\circ} \mathrm{C}\right)$ & Kedalaman $(\mathrm{m})$ & Stasiun \\
\hline $6 / 11 / 10$ & Pricanthus sagitarius & Bulan-bulan & 22 & 16,4 & 191,2 & 1 \\
$6 / 11 / 10$ & Monacanthidae sp. & Bulan-bulan & 22 & 20,6 & 148,2 & 2 \\
$6 / 11 / 10$ & Lyrocteis sp. & Nyoa burung & - & 19,4 & 164 & 3 \\
$6 / 11 / 10$ & Pristigenesys meyeri & Bulan-bulan & 20 & 19,0 & 171 & 4 \\
$8 / 11 / 10$ & Pricanthus sagitarius & Bulan-bulan & 21 & 19,2 & 191,3 & 1 \\
$8 / 12 / 10$ & Scorpaenidae sp. & Lepu & - & 12,2 & 219 & 2 \\
$8 / 12 / 10$ & Trachichthydae sp. & Ikan gora & 22 & 18,4 & 193,7 & 2 \\
$8 / 12 / 10$ & Antigonia carpos & Ikan Kupu-kupu & 18 & 10,9 & 216,6 & 3 \\
\hline
\end{tabular}

\section{DAFTAR PUSTAKA}

Aori, 2011. Sekilas tentang $A U V$. http://aorisanyustory. blogspot.com/2009/12/sekilas tentang auv_13.

Anonimous. 2011. Instrumentasi dan Hidroakustik. http://www.ilmukelautan.com/instrumentasi-danhidroakustik/instrumentasi-kelautan/395-pengembanganlengan-robot-robotic-arm-pada-remote-operating-vehiclerov-dengan-pengendalian-secara-manual.

Anonimous. 2011. Pemanfaatan Remotely Operated Vehicle untuk Penelitian Laut Dalam. http://ltmi.wordpress.com/ 2008/05/12/pemanfaatan-remote-operated-vehicle-rovuntuk-penelitian-laut-dalam. html. FSEA

Dwi, I. 2010. Karakteristik Air Laut. http://one-geo.blogspot. com. karakteristik-air-laut-ii.
Gross, G.M. 1990. Oceanography. Sixth Edition. Prentice Hall Inc., New Jersey.

Hunter, M. 1968. Underwater ROV-Remotely-OperatedVehicle. http://van-cuppy.blogspot.

Laevastu, T. dan M.L. Hayes. 1981. Fisheries Oceanography and Ecology. Fish. News (Books), London.

Nasir, M. 1993. Metode Penelitian. Ghalia Indonesia, Jakarta.

Suwardi. 2008. Underwater ROV. http://insansainsproject. wordpress.com/2008/04/08.html

Whephe. 2011. Laporan Praktikum DO Meter. http:// mahendrawhephe.blogspot.com.laporan-praktikum-dometer. 